\title{
CFD implementation and experimental validation of the Chen model for heat transfer in nucleate boiling
}

\author{
C. Paz, E. Suárez, M. Concheiro, A. Copo \& V. Tobio \\ Escuela de Ingeniería Industrial, University of Vigo, Spain
}

\begin{abstract}
The present paper describes a nucleate boiling model based on Chen's correlation, and posterior validation with experimental data. When using a heat exchanger with a liquid coolant, if the wall exceeds the saturation temperature of the liquid at system's pressure, it may boil, increasing the heat transfer law. The aim of this study is to validate the model developed with some experiments carried out in a heated flat probe. The proposed algorithm consists of a heat flux partition in two terms, one regarding the forced convection heat transfer existing in the free-boil area, and the other term considers the heat transfer increment due to the nucleate boiling. Consequently, general results show lower temperatures in the wall because of the increased heat flux, proved in several industrial components within these conditions. To achieve the model validation, some simulations were developed with the CFD software Ansys Fluent, configured with the same geometry and conditions as our experimental installation. Using a copper conduction, a heat flux up to $2 \mathrm{MW}$ is used to increase the temperature of a wall in contact with water, which flows through a $20 \mathrm{~mm}$ wide and $25 \mathrm{~mm}$ high duct. Heat transfer data are recorded while the temperature increases, allowing us to compare the boiling curves with the CFD boiling model results. Data comparisons show a good agreement with five cases studied at different conditions of system pressure and velocity and temperature inlet. An implementation of a widely used boiling model has been developed and its results have been validated with our experimental data, providing a good agreement under the specified conditions. The obtained results have shown an important improvement with respect to other multiphasic and standard models, offering better results simulating industrial components.

Keywords: nucleate boiling, Chen's model, CFD, Fluent.
\end{abstract}




\section{Introduction}

The limitation imposed to diesel and gasoline engines related to NOx emissions, forces the automotive industry to use and improve the Exhaust Gas Recirculation (EGR) system. It recirculates part of the exhaust gas after the combustion again to the cylinders, mixing it with the inducted air, decreasing the quantity of NOx created. The performance of this system is highly improved by cooling the recirculated gases before mixing them, decreasing the peak flame temperature inside the cylinder. Thus, the EGR cooler is an essential device in the automotive industry that using a coolant decreases the exhaust gases temperature before its entrance to the cylinder.

The cooler is subjected to some restrictions related to weight and mass that manufacturers have to consider, forcing them to design the cooler with a special shape and a minimum of engine auxiliary losses. These constraints can cause the wall temperature to increase due to the high heat transfers which are required through a small surface, and the coolant, typically water mixed with glycol, may boil when the wall exceeds the saturation temperature at system's pressure. During the first stage small bubbles grow up over the heated wall, increasing its size until buoyancy forces it to go beyond superficial forces, and bubbles move away from the wall. This situation usually occurs with subcooled flows, so the vapour created is condensed when it reaches the developed flow region.

The boiling phenomena increase the heat transfer ratio compared with forced convection, because of the agitation created by bubble nucleations and departures. Consequently, the restrictions described below force designers to take into account this situation, and incorporate boiling prediction techniques in their computational codes. Non-boiling codes will over predict the wall temperature if boiling appears because of this increment of the heat transferred.

Some models appeared during the last decades to try to predict the heat flux across a wall with nucleate boiling, ones with an empirical basis and others with some mechanistic fundamentals, but they still need some empirical correlations to calculate several properties. They were firstly created for the nuclear industry, where there is usually nucleate boiling within the coolant ducts at high pressures, but most of these are inaccurate and unstable for low pressure systems.

This paper shows the boiling model implementation carried out in Ansys Fluent, based on the Chen model that gave good results with some industrial components. To achieve the model validation, simulations were developed with the same geometry and conditions than our experimental installation, and results were compared with the experimental data, providing a good agreement under the specified conditions. Obtained results have shown an important improvement with respect to other multiphasic models implemented in commercial codes. 


\section{Numerical model implementation}

\subsection{Boiling model}

The model selected for this application is the Chen model, widely accepted for the automotive industry, Chen [1], and for our specific conditions. This algorithm consists of a heat flux partition in two terms, one regarding the forced convection heat transfer existing in the free-boil area, and the other term considers the heat transfer increment due to the nucleate boiling. These terms are multiplied by the factors $F, S_{f c}$, and $S_{s u b}$. Consequently, it can be written:

$$
q_{w}=F q_{f c}+S_{f c} S_{s u b} q_{n b}
$$

where $q_{w}$ is the local heat flux transferred, $q_{f c}$ is the forced convection term, and $q_{n b}$ is the nucleate boiling heat flux term, calculated by the following expressions:

$$
\begin{gathered}
q_{f c}=h_{f c}\left(T_{w}-T_{b}\right) \\
q_{n b}=h_{n b}\left(T_{w}-T_{s a t}\right)
\end{gathered}
$$

where $h_{f c}$ is the monophase convection heat transfer coefficient, and $h_{n b}$ is obtained with a correlation developed by Forster and Zuber [2]:

$$
h_{n b}=0.00122 \frac{k_{l}^{0.79} C_{p l}^{0.45} \rho_{l}^{0.49}}{\sigma^{0.5} \mu_{l}^{0.29} h_{l v}^{0.24} \rho_{v}^{0.24}}\left(T_{w}-T_{s a t}\right)^{0.25}\left[P_{\text {sat }}\left(T_{w}\right)-P_{\text {sat }}\left(T_{\text {sat }}\right)\right]^{0.75}
$$

Forced convection heat transfer is increased by the Reynolds Factor $F$ due to the liquid agitation, but will be taken as one due to the low volume fraction generated and the subcooled flow. According to the nucleate boiling heat flux, $S_{f c}$ is obtained with the suppression factor given by the Butterworth correlation [3], and $S_{\text {sub }}$ as defined by Steiner et al. [4]:

$$
\begin{gathered}
S_{f c}=\frac{1}{1+2.53 \cdot 10^{-6}\left(\operatorname{Re}_{l} F^{1.25}\right)^{1.17}} \\
S_{s u b}=\frac{T_{w}-T_{s a t}}{T_{w}-T_{b}}
\end{gathered}
$$

\subsection{Numerical implementation}

The software used for the numerical implementation is Ansys Fluent, which allow the user to define an algorithm with a User Defined Function (UDF) (Ansys [5]). With a specific macro, it is possible to access the linearized wall heat flux function and modify its coefficients to consider the partition developed by 
Chen when the temperature exceeds the saturation temperature at system pressure. The linearized expression is as follows:

$$
q_{w_{\text {lin }}}=c_{0}+c_{1} T_{1}-c_{2} T_{w}-c_{3} T^{4}
$$

where $T_{1}$ is the temperature of the cell adjacent to the wall inside the duct, and $T_{w}$ inside the solid, in contact with the fluid. In our case, the only heat transfer existing in the wall is due to convection, so the terms $c_{0}$ and $c_{3}$ will equal 0 , and $c_{1}=c_{2}=h_{f c}$. Our aim is to modify these terms, so $q_{w \text { lin }}$ equals the $q_{w}$ specified by Chen's model.

The implementation changes the coefficients after the end of each iteration, when the terms $c_{1}$ and $c_{2}$ were calculated. Then, new coefficients become:

$$
\left\{\begin{array}{l}
c_{0}^{\prime}=h_{n b} T_{s a t} S_{f c} S_{s u b} \\
c_{1}^{\prime}=c_{1} \\
c_{2}^{\prime}=c_{2}+h_{n b} S_{f c} S_{s u b} \\
c_{3}^{\prime}=0
\end{array}\right.
$$

If the boundary condition of the wall is set as a specified temperature, the model easily implements the value of $T_{w}$ for the terms $S_{s u b}$ and $h_{n b}$, and the heat transfer law is changed for each wall temperature. When the heat transfer is fixed, or the wall is specified as coupled, the temperature solved by the nonboiling model in the wall will be higher than the real one, obtaining wrong results. The new $T_{w}$ is calculated using a bisection method for each cell, which iterates the Chen heat transfer law looking for roots with a fixed heat flux. Consequently, with this method, the vast majority of real situations can be simulated.

\section{Validation}

\subsection{Experimental setup}

To obtain a reliable validation of the boiling model developed, it becomes necessary to have an experimental installation able to record temperature and heat flux data across a heated wall, and compare it with the equivalent model configured in Ansys Fluent.

There are some other experimental setups related in the literature with different geometries depending on its final application. For these experiments a $25 \mathrm{~mm}$ high and $20 \mathrm{~mm}$ wide rectangular section for the duct, similar to that used in Steiner et al. and Robinson et al. experiments, was chosen [4, 6]. A 355mm long piece was also added in order to ensure a developed flow before the heated wall duct. The installation has four resistances in contact with a copper piece that transfers the thermal energy to the upper surface, heating the liquid flowing inside the duct. A heat flux up to $2 \mathrm{MW}$ is used to boil deionized water. 
Three glasses were installed in the duct, useful for recording the bubble dynamics with a high-speed camera, and able to measure other boiling properties in the short-term future. Fig. 1 shows a CAD model of the duct used for the experiments.

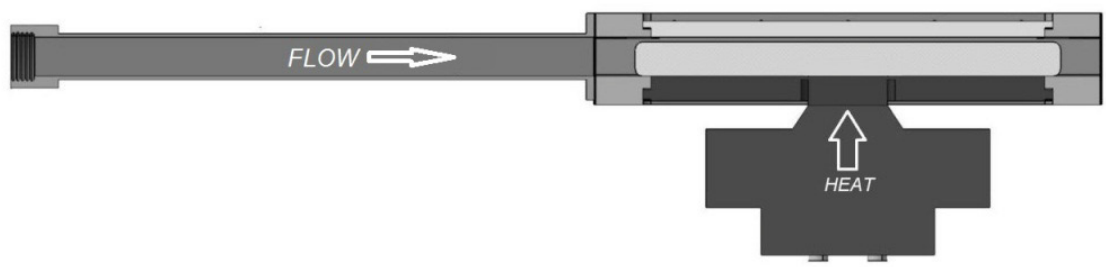

Figure 1: Model used for the experiments, showing the pre-entrance duct, the heated block, and the boiling zone.

\subsection{Methodology}

Some experiments were made with different boundary conditions, specially related to system's pressure, inlet velocity, and inlet temperature. The methodology followed consists in, once a stationary situation is reached, the resistances starting to conduct $1800 \mathrm{~kW}$ of electric power, being dissipated as thermal energy across the copper block. The piece starts to increase its temperature progressively, and using three thermocouples $1 \mathrm{~mm}$ below the surface, can measure its temperature. In addition, another thermocouple is situated $10 \mathrm{~mm}$ below the wall, and with the difference between the upper ones can measure the heat flux.

Data are recorded each 30 seconds until $30^{\circ} \mathrm{C}$ above the saturation temperature approximately, when the system starts to approach the CHF (Critic Heat Flux) point. Then, the resistances are switched off until everything reaches its initial situation.

\section{Results and discussion}

Five cases were studied at different conditions of system pressure, inlet velocity, and inlet temperature, representing boiling curves of both experimental data and predicted results with the developed model described before. The conditions studied are the next ones:

- Case 1: $Q=250 \mathrm{l} / \mathrm{h}, P=125 \mathrm{kPa}, T_{\text {in }}=80^{\circ} \mathrm{C}$

- Case 2: $Q=750 \mathrm{l} / \mathrm{h}, P=175 \mathrm{kPa}, T_{\text {in }}=85^{\circ} \mathrm{C}$

- Case 3: $Q=500 \mathrm{l} / \mathrm{h}, P=200 \mathrm{kPa}, T_{\text {in }}=80^{\circ} \mathrm{C}$

- Case 4: $Q=500 \mathrm{l} / \mathrm{h}, P=150 \mathrm{kPa}, T_{\text {in }}=85^{\circ} \mathrm{C}$

- Case 5: $Q=750 \mathrm{l} / \mathrm{h}, P=200 \mathrm{kPa}, T_{\text {in }}=90^{\circ} \mathrm{C}$

A good agreement was found with the cases described above, which has an error no higher than $15 \%$, a remarkable result for a nucleate boiling model. It shows 
good predictions of the onset of boiling and the heat flux increase with a similar inclination as the experimental data. Those results are shown in Fig. 2.
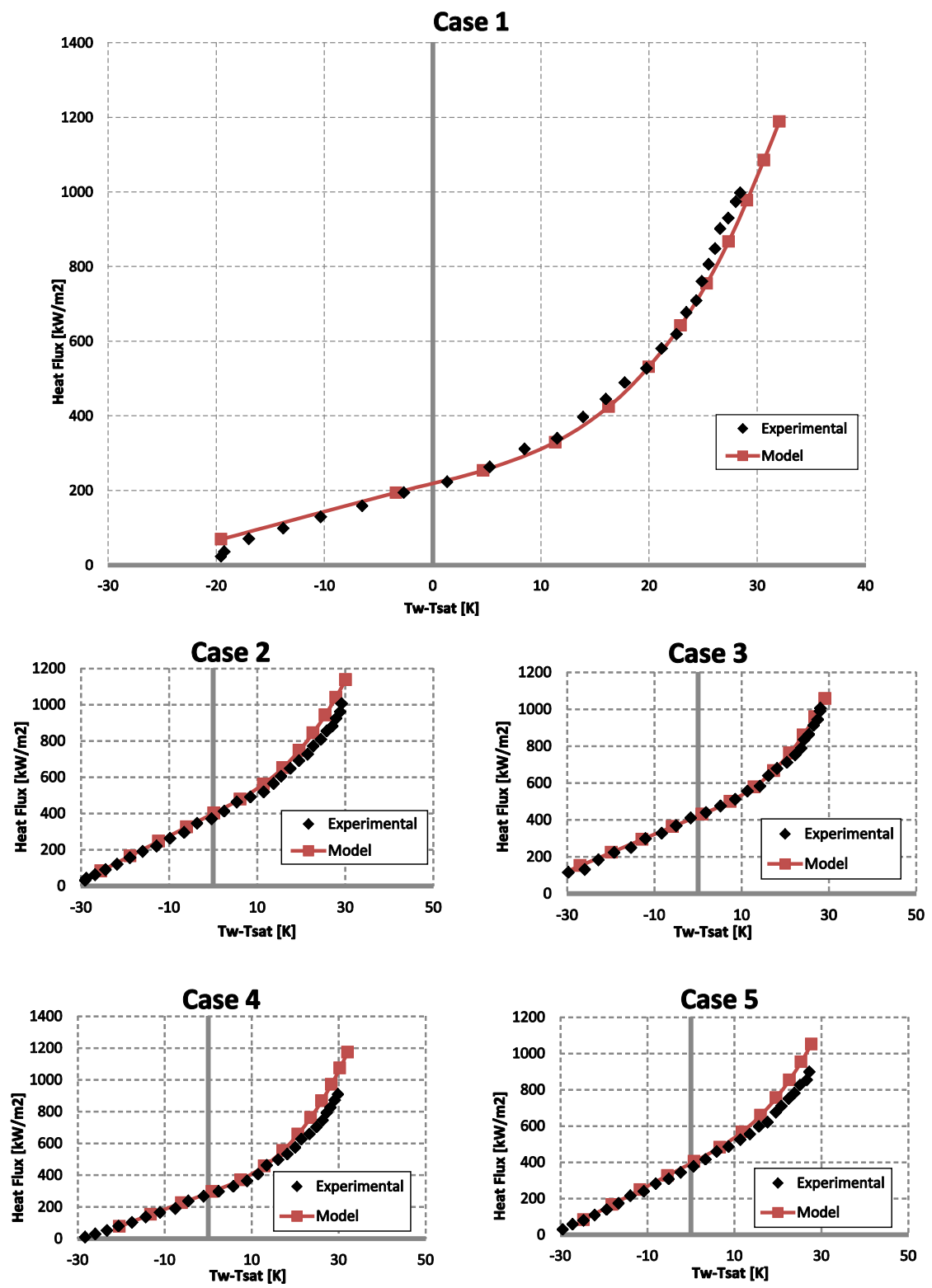

Figure 2: Comparison between the experimental data and results obtained with the developed model. 
Fig. 3 shows a comparison between the five cases studied, where it can be seen that all the curves reach the same point. This phenomenon, explained by Steiner et al. [4], appears at higher wall superheats when the influence of the convection heat transfer decrease and the evaporating effect prevails, becoming more and more pronounced. Then, the flow boiling curves approach the pool boiling curve, becoming practically independent of the actual flow rate.

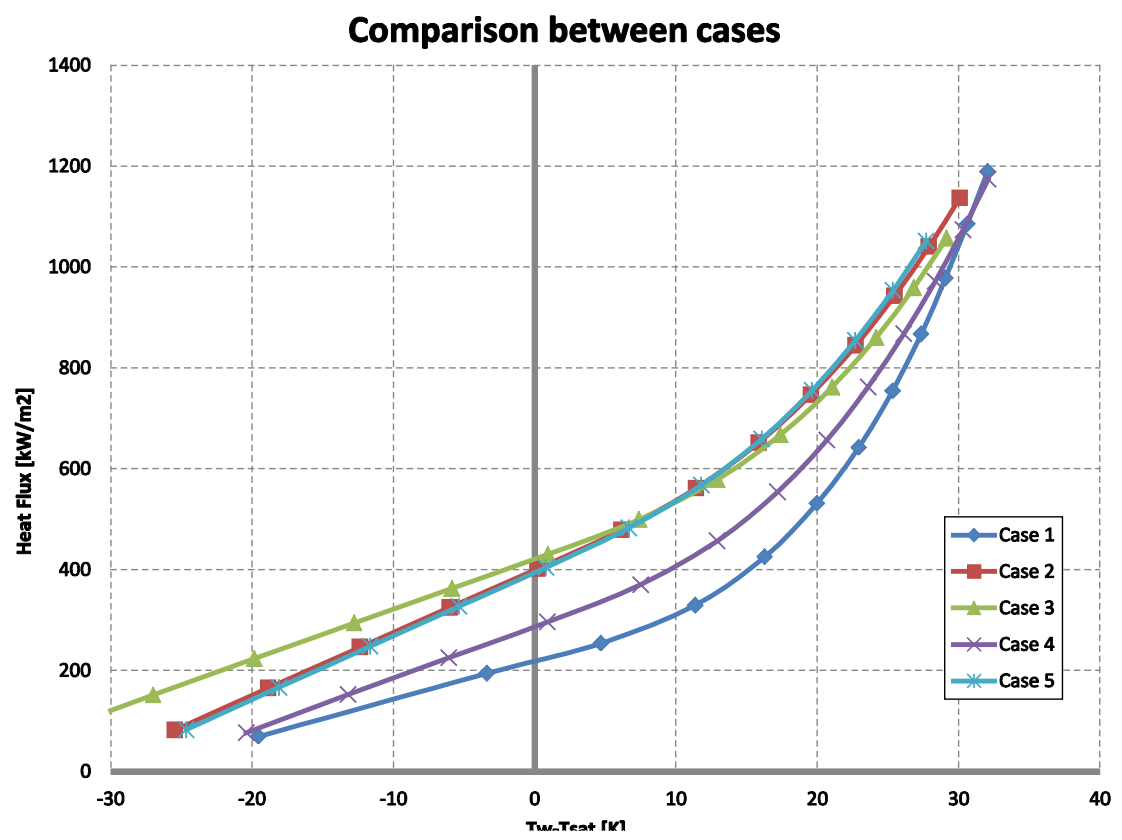

Figure 3: $\quad$ Comparison between predicted results obtained with the five cases.

\section{Conclusions}

In the present study an implementation of a widely used boiling model has been developed, and its results have been validated with our experimental data. The proposed Chen-based model is simpler than other models founded in the literature, providing faster and more stable results for the specified conditions. It allows making heat transfers simulations of a heat exchanger model with water, or water mixed with glycol, in contact with a wall that exceed the saturation temperature. A model with the same geometry and conditions than the experimental installation was configured, and the obtained results where compared showing an important improvement with respect to other multiphasic and standard models, offering better results simulating industrial components.

\section{Acknowledgement}

We gratefully acknowledge Borgwarner Turbo and Emission Systems for providing material and technical support. 


\section{Nomenclature}

\begin{tabular}{|c|c|}
\hline $\mathrm{H}$ & coefficients of the linearized wall heat flux equation [-] \\
\hline$D_{h}$ & hydraulic diameter [m] \\
\hline$F$ & correction factor $[-]$ \\
\hline$H$ & heat transfer coefficient [W/m² $\mathrm{K}]$ \\
\hline$h_{l v}$ & latent heat $[\mathrm{J} / \mathrm{kg}]$ \\
\hline$K$ & thermal conductivity $[\mathrm{W} / \mathrm{m} \mathrm{K}]$ \\
\hline $\mathrm{Nu}$ & Nusselt number [-] \\
\hline$P$ & pressure $\left[\mathrm{N} / \mathrm{m}^{2}\right]$ \\
\hline $\operatorname{Pr}$ & Prandtl number [-] \\
\hline$Q$ & specific heat transfer rate $\left[\mathrm{W} / \mathrm{m}^{2}\right]$ \\
\hline$R e$ & bulk flow Reynolds number [-] \\
\hline$S$ & suppression factor [-] \\
\hline$T$ & temperature $\left[{ }^{\circ} \mathrm{C}\right]$ \\
\hline$Q$ & flow rate $\left[\mathrm{m}^{3} / \mathrm{s}\right]$ \\
\hline$T_{\text {in }}$ & temperature inlet $\left[{ }^{\circ} \mathrm{C}\right]$ \\
\hline \multicolumn{2}{|c|}{ Greek symbols } \\
\hline$M$ & dynamic viscosity $[\mathrm{kg} / \mathrm{m} \mathrm{s}]$ \\
\hline$P$ & density $\left[\mathrm{kg} / \mathrm{m}^{3}\right]$ \\
\hline$\Sigma$ & surface tension $\left[\mathrm{kg} / \mathrm{s}^{2}\right]$ \\
\hline \multicolumn{2}{|c|}{ Subscripts } \\
\hline $1^{o}$ & values corresponding to cells closest to the wall \\
\hline$B$ & bulk \\
\hline$F_{C}$ & forced convection \\
\hline$L$ & liquid phase \\
\hline Lin & linearized \\
\hline$N b$ & nucleate boiling \\
\hline Sat & saturation \\
\hline Sub & subcooling \\
\hline$V$ & vapor phase \\
\hline$W$ & Wall \\
\hline
\end{tabular}

\section{References}

[1] Chen, J.C., Correlation for Boiling Heat Transfer to Saturated Fluids in Convective Flow. Industrial and Engineering Chemistry Process Design and Development, 5, pp. 322-329, 1966.

[2] Forster, H.K. and Zuber, N., Dynamics of vapor bubbles and boiling heat transfer. AIChE Journal, 1(4), pp. 531-535, 1955.

[3] Butterworth, D., The correlation of cross flow pressure drop data by means of a permeability concept. UKAEA Report AERE-R9435, 1979. 
[4] Steiner, H., Kobor, A. and Gebhard, L., A wall heat transfer model for subcooled boiling flow. International Journal of Heat and Mass Transfer, 48, pp. 4161-4173, 2005.

[5] Ansys, Ansys Fluent User Guide, Release 14, Ansys Inc.

[6] Robinson, K., Hawley, J.G. and Campbell N.A.F., Experimental and modelling aspects of flow boiling heat transfer for application to internal combustion engines. Proc. of the Institution of Mechanical Engineers, Part D: Journal of Automobile Engineering, 217(10), pp. 877-889, 2003. 